\title{
Service delivery system design: characteristics and contingencies
}

\begin{abstract}
Purpose: The aim of this paper is to explore and empirically investigate the characteristics and contingencies of service delivery system design.

Design/methodology/approach: Informed by the service strategy triad, a single embedded case study was designed to explore empirical data on four target markets, four service concepts, and on the design characteristics of the corresponding four service delivery systems. Data was collected in a market leading organisation in the B2B sector within the power industry. The service delivery systems comprise processes that sell electricity contracts and processes that bill against those contracts.
\end{abstract}

Findings: First, the findings indicate what design characteristics are contingent upon the degree of customisation of the service concept. We show how this contingency has implications for the extents of employee skills, employee discretion, task routineness, automation, and for front office - back office configurations. Second, we challenge the consensus that low customer-contact processes are designed for the purpose of efficiency. Third, our findings contradict Metters and Vargas (2000) who state that it is not possible to have different front office - back office configurations in a single organisation.

Research limitations/implications: While there are major interactions between the four service delivery systems supporting each individual service concept, this research does not examine the trade-offs between the various possible designs of these service delivery systems.

Practical implications: The study emphasises the importance of considering the complexity of the service offering, the customer relationship strategy, and of taking a process-orientation to address service delivery system design.

Originality/value: This research extends current understanding of service delivery system design characteristics and contingencies. We show how design characteristics are contingent on the service concept. Research propositions are formulated to emphasise this contingency. Additionally, we report findings which challenge existing front office - back office design theory.

Keywords: service design, service concept, service delivery system, strategic alignment 


\section{Introduction}

The competitiveness of service businesses is contingent, at least in part, on the design and configuration of the service delivery system through which the service concept, and the value proposition inherent within it, is provided to target customers (Frei and Harker, 1999; Johnston and Clarke, 2005; Verma et al., 2002). The notion of 'alignment' transcends much of the extant literature on service design. Congruency between target market, service concept, and service delivery system design is often emphasised as a means to successfully deploy business strategy and attain levels of performance in customer satisfaction, retention, and overall profitability. The service strategy triad (Roth and Menor, 2003), synthesised from extant theory, provides a commonly cited framework for the conceptualisation of this alignment issue, and provides a useful starting point for the exploration of service delivery system design characteristics and contingencies. Since empirical data on the components of the service strategy triad is explored in this article, these elements must be defined. First, the notion of target markets addresses the question of "who" is the right customer. Second, the service concept can be described as the mix of tangible and intangible elements comprising the delivered service. It defines "what" is being provided to the customer. Alternative terms include service offering, service package, and service bundle. Third, the service delivery system is concerned with "how" the service concept is provided to the customer. It encompasses the structure (e.g. facilities, equipment) and infrastructure (e.g. skills, policies) to deliver the service concept.

This research addresses the question of what design characteristics enable the service delivery system to provide the service concept to the customer. Roth and Menor (2003) note that limited empirical evidence exists on the issue of strategic service alignment. Two studies provide empirical support for the service strategy triad and stress that it is necessary to align service concept and service delivery system design to achieve superior performance (Karwan et al., 2006; Silvestro and Silvestro, 2003). While valuable for emphasising the need for alignment, these studies do not provide the specific design characteristics that enable service organisation to realise the alignment. Additionally, they do not consider the impact of different service concepts on the design characteristics of the corresponding service delivery systems.

The impetus to undertake this research emerged during a review of the B2B service delivery system of a large telecommunications company. Here we observed significant complexity in 
the way a multiplicity of both standardised and customised service concepts (aligned to meet the requirements of defined market segments) was delivered through a single, homogeneous delivery system. The legacy delivery system comprising IT billing engine constraints, combined with process rigidities (designed for the delivery of standardised service concepts), resulted in escalating costs, delayed implementation, and in some cases inaccurate billing. It is arguable that the delivery system exhibited alignment with the standardised service concepts but also simultaneously failed to obtain alignment with customised service concepts - resulting in poor performance. While we acknowledge the 'alignment' imperative of the service strategy triad considerable challenges exist in the design of service delivery systems in practice.

Many authors have recognised the importance of the design of service delivery systems and have also identified limited theoretical development in the area (Tax and Stuart, 1997; Goldstein et al. 2002; Gummesson, 1990; Hill et al., 2002; Johnston, 1999; Kwortnik and Thompson, 2009). Consequently, a greater intensity of research is repeatedly requested (Chase, 1996; Chopra et al., 2004; Nie and Kellogg, 1999). While an increasing intensity of research effort has been identified throughout the 1997-2002 period (Machuca et al., 2007), further calls for research, particularly from an operations management perspective, have been requested (Roth and Menor, 2003). Specifically, Zomerdijk and de Vries (2007, p.128) emphasise that "the impact of contingency variables, such as the service being delivered," on service delivery system design is a primary candidate for future research. This view is echoed by Safizadeh et al. (2003) who argue that future research should explore the influence of the service concept on process design characteristics.

The proposed contingent relationship between service concept and service delivery system design characteristics has been postulated in many conceptual frameworks. These include models of strategic service alignment (Armistead, 1990; Goldstein et al., 2002; Roth and Menor, 2003), service classification schemes (Collier and Meyer, 1998; Kellogg and Nie, 1995; Tinnilae and Vepsäläinen, 1995), and service design models (Edvardsson and Olsson, 1996; Johnston and Clark, 2005). The consensus in the theoretical literature is that the design of the service delivery system should support the realisation of the service concept and, as a result, that different service concepts require different approaches to the design of service delivery systems. Despite this, limited empirical research investigating the influence of the service concept on the design of the service delivery system has been reported. Currently, it is unclear what are the design characteristics of the service delivery system and how the design 
characteristics are contingent on the service concept. The research presented here directly addresses these issues. The aim of this paper is to provide an understanding of the characteristics and contingencies of service delivery system design.

The remainder of this article is structured as follows. First, the relevant literature is reviewed to highlight the gaps in knowledge, define the research variables, and to formulate the research question. Second, we discuss research design and research methodology. Third, we present the results of data analysis and address the research question. Fifth, we discuss the implications of our research for theory and practice, emphasising some key propositions, and discuss the limitations. Finally, we present the conclusions.

\section{Literature review}

Aligning service concept and service delivery system design

The service design literature emphasises the importance of conceptual models of strategic service alignment (Goldstein et al., 2002; Heskett, 1987; Roth and Menor, 2003). These models broadly discuss the importance of aligning business strategy, the service concept, and the design of the service delivery system. Roth and Menor (2003) synthesise an integrated model of service design: the service strategy triad (Figure 1). The triad emphasises that the service concept is developed to address the requirements of a target market, and that service concept specifications, in turn, influence the design of the service delivery system. The triad reconciles two distinct perspectives of marketing and operations and highlights the need for an integrated approach to service design. In a seminal article Heskett (1987) explicates the relationship between strategy and service design: it consists of identifying the target market, developing a service concept for the targeted segment, determining an operations strategy to support the service concept, and designing a service delivery system to support the operating strategy. Similarly, Goldstein et al. (2002) argue that service design decisions follow strategic requirements and ensure that the service delivery system supports the realisation of the service concept. The relationship between the service being offered (i.e. the service concept) and the delivery system that provides the service has been suggested in several conceptual models (Armistead, 1990; Collier and Meyer, 1998; Kellogg and Nie, 1995; Shostack, 1987). 


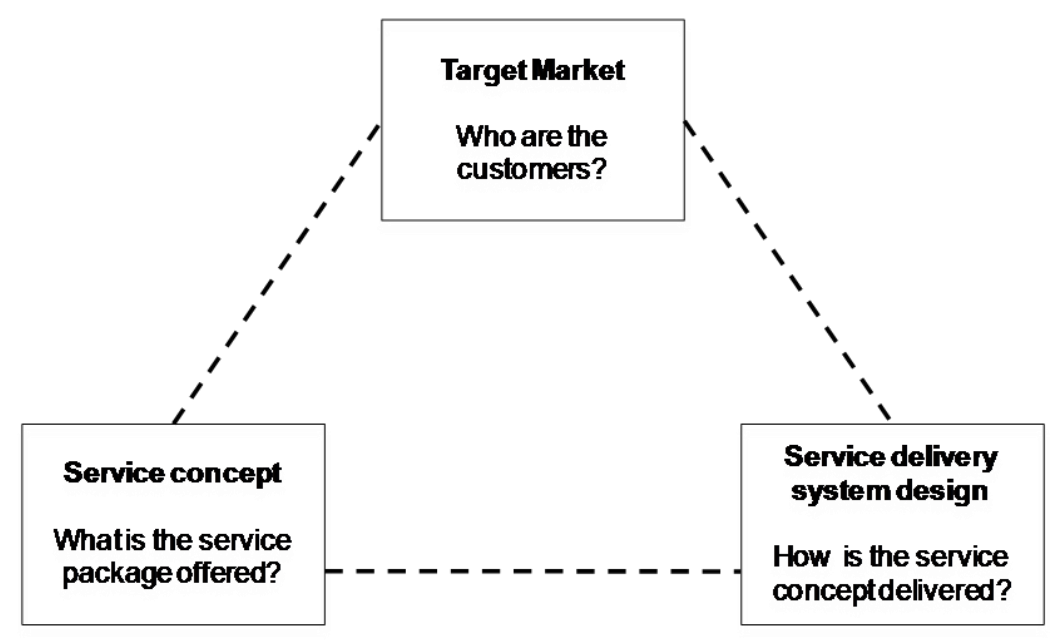

Figure 1: The service strategy triad

In addition, previous work has emphasised that the alignment of the service concept with service system design is a pre-requisite for improved performance (Heskett, 1987; Karwan and Markland, 2006; Kellogg and Nie, 1995). For instance, Roth and Menor (2003) argue that an organisation which realises the alignment will benefit from increased competitiveness and improved competitive capabilities. A study by Silvestro and Silvestro (2003) provides empirical evidence that not achieving alignment has a detrimental effect on service delivery performance. They find that operating a misaligned delivery system has critical implications for the capability of the organisation to deliver the expected service concept and to achieve its operational objectives.

\section{Service concept}

The service concept relates to the characteristics of the service offered to the target market. Sasser et al. (1978) first described the service concept as "the bundle of goods and services sold to the customer and the relative importance of each component to the consumer" (p.14). The dominant view in the literature is that the service concept can be seen as a package made up of a set of tangible and intangible elements (Karwan and Markland, 2006). In other words, it is defined in terms of its constituent parts (Goldstein et al., 2002) and the most common way of classifying the service concept relates to the degree of customisation of these elements (Zomerdijk and de Vries, 2007). Furthermore, the service concept conveys the benefits and value provided to customers (Collier, 1994). From this perspective, it can be regarded as the company's value proposition (Brohman et al. 2009; Edvardsson and Olsson, 1996; Heskett, 1987). Therefore it follows that different service concepts, representative of different degrees 
of customisation, require different configurations of the service delivery system (Roth and Menor, 2003).

\section{Service delivery system design}

The design of the service delivery system addresses the question of "how" the service concept is delivered to target customers (Tax and Stuart, 1997). A large number of issues need to be considered to design a service delivery system. Heskett (1987) suggests that design choices revolve around the role of people, technology, facilities, equipment, layout, service processes, and procedures. Similarly, Ramaswamy (1996) suggests that service system design decisions concern the service facilities where the service is provided and the processes through which the service is delivered. Since a service system is characterised by the relationships occurring between people, service processes, and physical elements, these dimensions must be considered jointly to effectively plan and conceive the service delivery system (Tax and Stuart, 1997). Roth and Menor (2003) offer a compelling account of design choices for the service delivery system. They argue that design decisions include aspects of structure, infrastructure, and integration. Structural choices relate to the physical aspects of the service system such as facilities, layout, and equipment. Infrastructural choices refer to the role of service providers such as job design, policies, and skill set. Integration choices concern co-ordination issues, service supply chains, and adaptive mechanisms. In summary, the literature highlights the major issues of concern for service delivery system design which include the role of people, the role of technology and equipment, and the role of location and layout.

To further conceptualise these issues it is useful to consider existing service classification schemes as they provide additional insights into the design of service delivery systems (see Cook et al., 1999 for a comprehensive review). Collier and Meyer (2000) argue that service classifications can inform the configuration of a service delivery system to best meet customer requirements. Specifically, classification schemes help in the identification and articulation of a set of design characteristics for different types of service systems (Collier and Meyer, 1998; Safizadeh et al., 2003; Verma and Thompson, 1999; Wemmerloev, 1990). Table 1 provides a summary of the major design characteristics discussed in existing service classifications and associates them with categories of service delivery systems. This framework of design characteristics offers valuable insights into the dimensions to be explored in the empirical phase of the research. 


\begin{tabular}{|c|c|c|c|c|}
\hline $\begin{array}{l}\text { Service delivery system } \\
\text { / Design characteristics }\end{array}$ & $\begin{array}{l}\text { Professional } \\
\text { Service }\end{array}$ & $\begin{array}{l}\text { Service } \\
\text { Shop }\end{array}$ & $\begin{array}{l}\text { Service } \\
\text { Factory }\end{array}$ & Source \\
\hline \multicolumn{5}{|l|}{ Role of people } \\
\hline Level of skills & High & Medium & Low & $\begin{array}{l}\text { Kellogg and Nie (1995); } \\
\text { Silvestro (1999); Chase and } \\
\text { Tansik (1983); Buzacott } \\
(2000)\end{array}$ \\
\hline $\begin{array}{l}\text { Degree of employee } \\
\text { discretion }\end{array}$ & High & Medium & Low & $\begin{array}{l}\text { Silvestro et al. (1992); } \\
\text { Buzacott (1990); Lovelock } \\
\text { (1983) }\end{array}$ \\
\hline \multicolumn{5}{|l|}{$\begin{array}{l}\text { Role of technology and } \\
\text { equipment }\end{array}$} \\
\hline Degree of routineness & Low & Medium & High & $\begin{array}{l}\text { Wemmerloev (1990); } \\
\text { Buzacott (2000) }\end{array}$ \\
\hline Degree of automation & Low & Medium & High & $\begin{array}{l}\text { Kellogg and Nie (1995); } \\
\text { Schmenner (1986); } \\
\text { Silvestro et al. (1992); Apte } \\
\text { and Vepsaelaeinen (1993) }\end{array}$ \\
\hline \multicolumn{5}{|l|}{$\begin{array}{l}\text { Role of location and } \\
\text { layout }\end{array}$} \\
\hline Location & $\begin{array}{l}\text { Distributed } \\
\quad \text { (near } \\
\text { customer) }\end{array}$ & $\begin{array}{l}\text { Non } \\
\text { applicable }\end{array}$ & $\begin{array}{l}\text { Centralised } \\
\text { (remote from } \\
\text { customer) }\end{array}$ & $\begin{array}{l}\text { Chase and Tansik (1983); } \\
\text { Kellogg and Nie (1995); } \\
\text { Wemmerloev (1990); } \\
\text { Cohen et al. (2000) }\end{array}$ \\
\hline FO-BO configurations & $\begin{array}{l}\text { Service- } \\
\text { oriented }\end{array}$ & $\begin{array}{c}\text { Non } \\
\text { applicable }\end{array}$ & $\begin{array}{l}\text { Efficiency- } \\
\text { oriented }\end{array}$ & Metters and Vargas (2000) \\
\hline
\end{tabular}

Table 1: Design characteristics of service delivery systems (adapted from Johansson and Olhager, 2004)

Whilst service system design research is growing, in particular with respect to the configuration of front office (FO) - back office (BO) work, empirical studies addressing the design of service systems in relation to the service concept remain limited. Silvestro and Silvestro (2003) point to the necessity of aligning service concept and service delivery system. They analyse the alignment between service concept, operational objectives, and service delivery system design in an underperforming public sector service organisation. They found that the organisation failed to translate their service concept into explicit service specifications on the basis of which the service delivery system may be designed. Another study by Karwan and Markland (2006) provides further support for the service strategy triad as a conceptual model. They examine the design of front-office and back-office activities and the use of technology in the service delivery system of government operations. Their empirical evidence shows the role of strategic service alignment in improving the performance of public organisations. Furthermore, Zomerdijk and de Vries (2007) suggest a 
link between service concept and service delivery system design but their work is deficient in specifying critical contingencies and resulting design characteristics. They analyse design decisions which include customer contact, FO-BO decoupling, and employee grouping in three separate service delivery systems. While their empirical work does not investigate how the service concept influences design decisions, they note the importance of considering this contingency when designing a service delivery system. Finally, Safizadeh et al. (2003) explore the design and operation of service delivery processes in the financial services industry. Specifically, they study process design characteristics, performance outcomes, customer involvement, and competitive priorities in 108 service processes. Although the study does not directly investigate the relationship between the service offering and the design characteristics of service delivery processes, the authors emphasise the importance of the service concept in design considerations.

Extant theory and observations from practice suggest that the design of service delivery systems requires further exploratory research. Theoretical models of service design, such as the service strategy triad, are useful for emphasising the need for alignment between the service concept and the design of the service delivery system. The triad, however, provides little assistance in specifying the design characteristics which are necessary in order to realise the alignment. Additionally, as recently pointed out by several SOM scholars (Safizadeh et al., 2003; Zomerdijk and de Vries, 2007) the influence of the service concept on the design of the service delivery system requires further empirical investigation. An exploratory research design was therefore formulated in pursuit of key design characteristics and contingencies. This article reports on the results obtained from exploratory research to address the question: what are the design characteristics and contingencies of service delivery systems? In addressing this research question, we explore empirical data on target markets, service concepts, and service delivery system design characteristics as denoted in the service strategy triad. The research focuses on what are the design characteristics of the service delivery system and also how these characteristics are contingent upon the service concept. Specifically, we focus on the degree of customisation of four distinct service concepts and how they influence the design characteristics of the corresponding service delivery systems. 


\section{Research methods}

This research employs a single embedded case study design. The approach provides opportunity to obtain rich insights necessary for theory development in service design (Karwan and Markland, 2006; Tax and Stuart, 1997) and to formulate research propositions that can be used as a platform for future research (Eisenhardt, 1989). Furthermore, the case method allows the questions of "what" and "how" to be addressed which helps to provide a detailed view of the topic and facilitates the construction of an as-near-as-complete picture of the phenomenon (Meredith, 1998).

The research was undertaken in a market leading organisation within the power industry. The case company is a leading electricity supplier that provides a range of electricity services in the business-to-business sector in the UK. The company sells contracts for electricity provision and bills against these contracts. We sought out a market leader in a competitive industry to maximise the opportunity to identify characteristics of service delivery systems closely associated with market leading performance. The selected company is part of one of Europe's largest power companies. The group leads the European utilities industry, both in terms of revenues and generation capacity. The case organisation was the market leader in the UK in terms of volume of electricity sold in 2009. It has over performed its competitors in terms of customer satisfaction and customer loyalty for a number of years. Specifically, the organisation has been consistently ranked in the top three electricity suppliers in Datamonitor's customer satisfaction ratings ${ }^{1}$ since 2004 . Customer loyalty has also averaged $88 \%$ between 2006 and 2009 against a market average of $77 \%$ during the same period. A single-case design was also pursued to maximise access to empirical evidence (Yin, 2003). The company provided the research team with a corporate email account and unrestricted access to the organisation's intranet and staff. This facilitated a complete immersion in data over a period of 16 months.

An embedded case study design contains multiple units of analysis (Yin, 2003). The research explores four distinct service concepts and the associated four service delivery system. The service concepts represent distinct service offerings which are referred to as default, standard,

\footnotetext{
${ }^{1}$ Datamonitor's research probes customer satisfaction across six core competencies: contracting, billing, account management, query handling, flexibility, and support. Customer satisfaction interview questions cover the importance of the competency for the customer and the customer's experience of the competency. The seven largest electricity suppliers in the B2B sector are then ranked based on their customer satisfaction scores. (http://www.datamonitor.com/store/Product/q1_2008_energy_buyer_survey_major_energy_user_power_custom er_satisfaction?productid=BFEN0378)
} 
flexible, and bespoke contracts in the case organisation. The unit of analysis of an embedded case is represented by a sales process and by a billing process that together make up the service delivery system supporting each individual service concept. We distinguish between 'Sales' and 'Delivery' processes as we found that it was a useful way of conceptualising the organisation's service delivery system. This conceptual approach is consistent with previous empirical research on service delivery system design (e.g. Metters and Vargas, 2000; Zomerdijk and de Vries, 2007). For each service concept considered, a sales process and the corresponding billing process are studied. Thus, there are four embedded cases which represent four "service concept - processes" pairs.

Data collection was guided by a case-study protocol detailing the research variables, questions, procedures and potential sources of information to ensure that robust and valid data was captured consistently across the cases. The research protocol can be found in the Appendix. Semi-structured interviews lasting between 45 minutes and 1h50 were conducted. Multiple informants, of varying seniority and from a variety of functions, were interviewed including sales managers, sales assistants, marketing managers, service quality managers, credit control managers, customer service advisors, billing managers, service managers, operations managers, IT specialists, and process management experts. Follow-up interviews were often required to fill the gaps in information and to clarify some uncertainties. Detailed interview reports were written to consolidate and summarise acquired knowledge. In addition, we collected extensive internal company information which is regarded as objective because the data is produced outside of the research. This data includes process documentation, HR documentation, marketing documentation, performance documentation, and customer-specific information such as Service Level Agreements and emails exchanges. In total over 900 pages of text, from 97 company documents together with 41 separate interviews formed the dataset from which sense-making was sought. Triangulation was achieved through collecting data from multiple sources (i.e. interviews, documentary evidence, direct observation, and secondary data), collecting data from multiple informants, mixing qualitative and quantitative evidence, and having multiple investigators involved in the data collection process to offer different viewpoints (Voss et al., 2002).

Data analysis took place in three phases - data reduction, data display, and conclusion drawing - following the guidelines of Miles and Huberman (1994). Phase one consisted of documenting and coding the data. Interview data was transcribed and other data were either summarised or kept in original form. Each transcript was analysed based on the research 
protocol and relevant information was extracted, compiled, and summarised in an interview report. Comprehensive process models of the service delivery systems supporting each service concept were then produced using IDEF-0 (see Congram and Epelman, 1995 for a description of the IDEF modelling methodology) and associated descriptions were developed. Data coding commenced following the validation of the process models by the Project Champion. This step consisted of coding interview transcripts, interview reports, company documentation, and field notes. Thematic coding (Flick, 2006) was used to make sense of the raw data. In phase two we produced a set of tabular displays to systematically present the relevant information about the design variables. The coded data was then organised into caseoriented tables following the structure of the research protocol to display relevant case information and to document how each case addressed the research variables. In parallel, a detailed, descriptive summary was produced in order to become "intimately familiar with each case" (Eisenhardt, 1989). Four case-study reports were sent to the Project Champion for review. Validated reports formed a robust basis for supporting the cross-case data analysis. Phase three was concerned with ranking the cases and classifying them across the research variables. In the cross-case analysis, the cases studied were compared with one another. Construct-oriented tables were produced and used to compare, measure, and rank the research variables. In the process of building data displays, each variable was ranked from 1 to 4 using an ordinal scale. This enabled the study to draw cross-case conclusions about each variable. After constructs were classified, final case-oriented tables were built to summarise the results.

\section{Data analysis}

In this section the elements of the service strategy triad - target markets, service concept, and service delivery system design - are analysed and discussed in turn within the context of the case organisation.

\section{Target markets}

The target markets of the organisation encompass a range of small to medium businesses and large companies which are primarily segmented on the basis of their profitability and of their level of electricity consumption (i.e. a function of the number of sites to supply and of the sites' consumption profiles). Table 2 provides the key figures of each target market. 


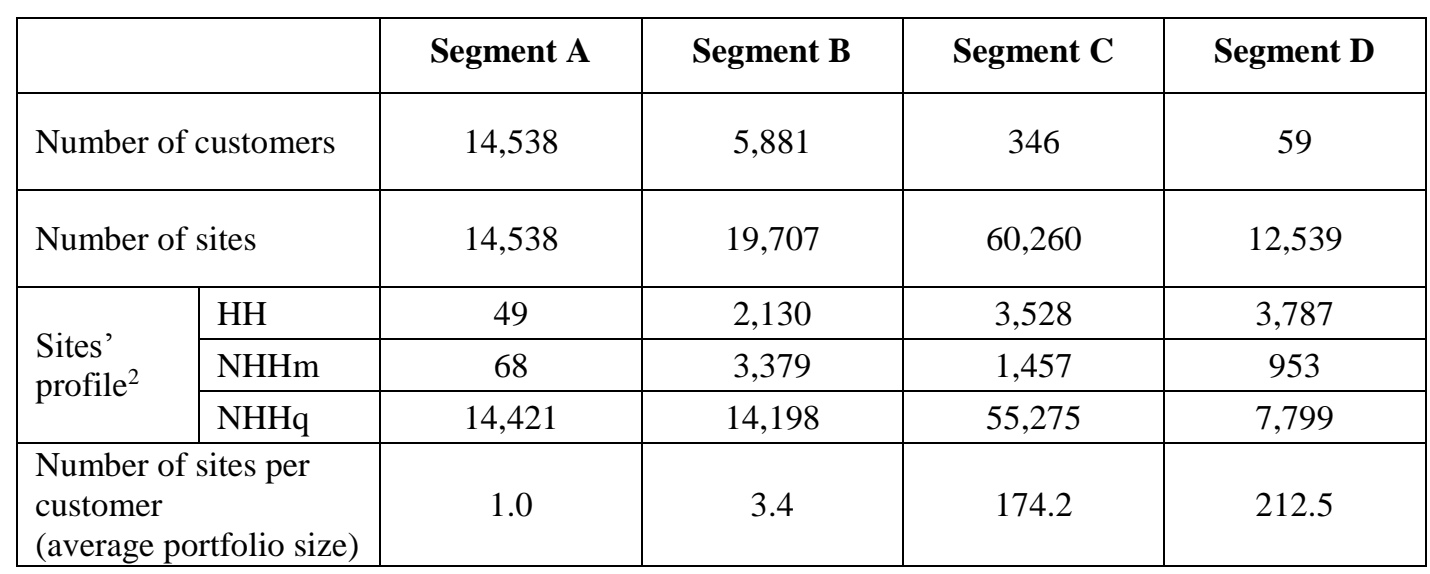

Table 2: Characteristics of target markets

There are 14,538 customers in segment A which accounts for $1.3 \%$ of electricity volume. Small businesses using very low volumes of electricity such as public houses and restaurants make up this group. Segment B comprises 5,881 customers which represent $13.1 \%$ of electricity volume. Gross Margin (GM) contribution falls under $£ 10 \mathrm{k}$ p.a. per customer. These are small and medium businesses with few supply points such as local commercial outlets and small family-run organisations. There are 346 customers in segment $\mathrm{C}$ which accounts for $35.8 \%$ of electricity volume. These are large organisations consuming significant volumes of electricity, such as utilities and telecommunications companies. Each customer has many sites with different profiles in their portfolio. GM contribution is usually between $£ 50 \mathrm{k}-300 \mathrm{k}$ p.a. per customer. Finally, 59 customers make up segment D which accounts for $18.5 \%$ of electricity volume. This segment includes very large organisations with very large consumption levels (i.e. over $80 \mathrm{GWh} / \mathrm{year}$ ) such as industrial and major energy users. GM contribution is usually higher than $£ 300 \mathrm{k}$ p.a. per customer. Customers have many supply points with different characteristics in terms of metering requirements and voltage capacities. This segment was created to address the complex requirements of some high-profile customers who previously belonged to segment $\mathrm{C}$.

\section{Service concepts}

Following Apte and Vepsäläinen (1993), the classification and measurement of the extent of customisation of the service concepts was based on two dimensions. Customised services are typified by numerous, configurable parameters and require close customer relationships.

\footnotetext{
${ }^{2} \mathrm{HH}$ : half-hourly (consumption data is recorded every half-hour and transmitted to the case organisation every month); NHHm: non-half-hourly monthly (consumption data is recorded and transmitted every month); NHHq: non-half-hourly quarterly (consumption data is recorded and transmitted every quarter)
} 
Standardised service concepts are characterised by limited, configurable parameters and a transaction-based customer relationship strategy. Case study data is provided in Tables 3 and 4. The data analysis resulted in the ordinal classification of service concepts A, B, C, and D along a standardisation-customisation continuum.

Service concept $\mathrm{A}$ is a generic service offering with no options available. Customers are automatically provided with a default contract whose price is fixed by the service provider. There are no value-added products that may be attached to the core offering. Similarly, there are no individual members of staff who have personal responsibility for individual customer accounts. There is no planned encounter between the customer and the organisation. In the sales process, a one-off, single exchange occurs through the mail. The customer relationship strategy is purely transactional.

Service concept B is a restricted service offering. It is composed of a set of core standard components to which a limited number of options (i.e. 11) can be added such as contract duration or some pricing elements. Each customer is allocated to an individual contract manager who manages the sales process. 35 contract managers deal with 5,881 customers. In sales, there is one planned encounter that occurs near the end of the contract when the company pro-actively starts the renewal process. Usually, these exchanges are short, one-off encounters for discussing and negotiating contract terms. However, there is no specific individual assigned to the management and maintenance of billing accounts. The customer relationship is essentially transaction-based.

Service concept $\mathrm{C}$ is a selective offering. While some parts of the offering are standardised, the customer has the opportunity to select from a large number of predetermined options (i.e. 28). Providing flexible-purchasing ${ }^{3}$ offerings requires developing a close, personalised relationship with the customer. 12 contract managers manage the sales process for 346 customers. Formal negotiations for contract renewal occur every 6 months. There are also monthly meetings to discuss prices, contract terms, and new requirements. In addition, a limited number of customers rely on a "virtual team" dedicated to managing individual customer accounts.

Service concept $\mathrm{D}$ is unique. The customer defines and determines the characteristics of the entirety of the service offering. From a pricing perspective, bespoke contracts are flexible-

${ }^{3}$ Flexible contracts provide the ability to spread energy purchasing according to an energy price risk management strategy. 
purchasing offerings. Additionally, Service Level Agreements (SLA) include prices, contract duration, contract terms, bill validation, billing cycles, and tailor-made performance reports. Customers are involved in the development of new options. This requires intensive customer involvement. 4 contract managers deal with 59 customers. Recently, some customers have entered into evergreen agreements which are contracts with no end date. Moreover, the billing accounts of all customers are personally managed by a dedicated Service Development Manager. Service reviews take place every quarter or every month to discuss service delivery performance. This demonstrates the long-term, strategic nature of the relationship.

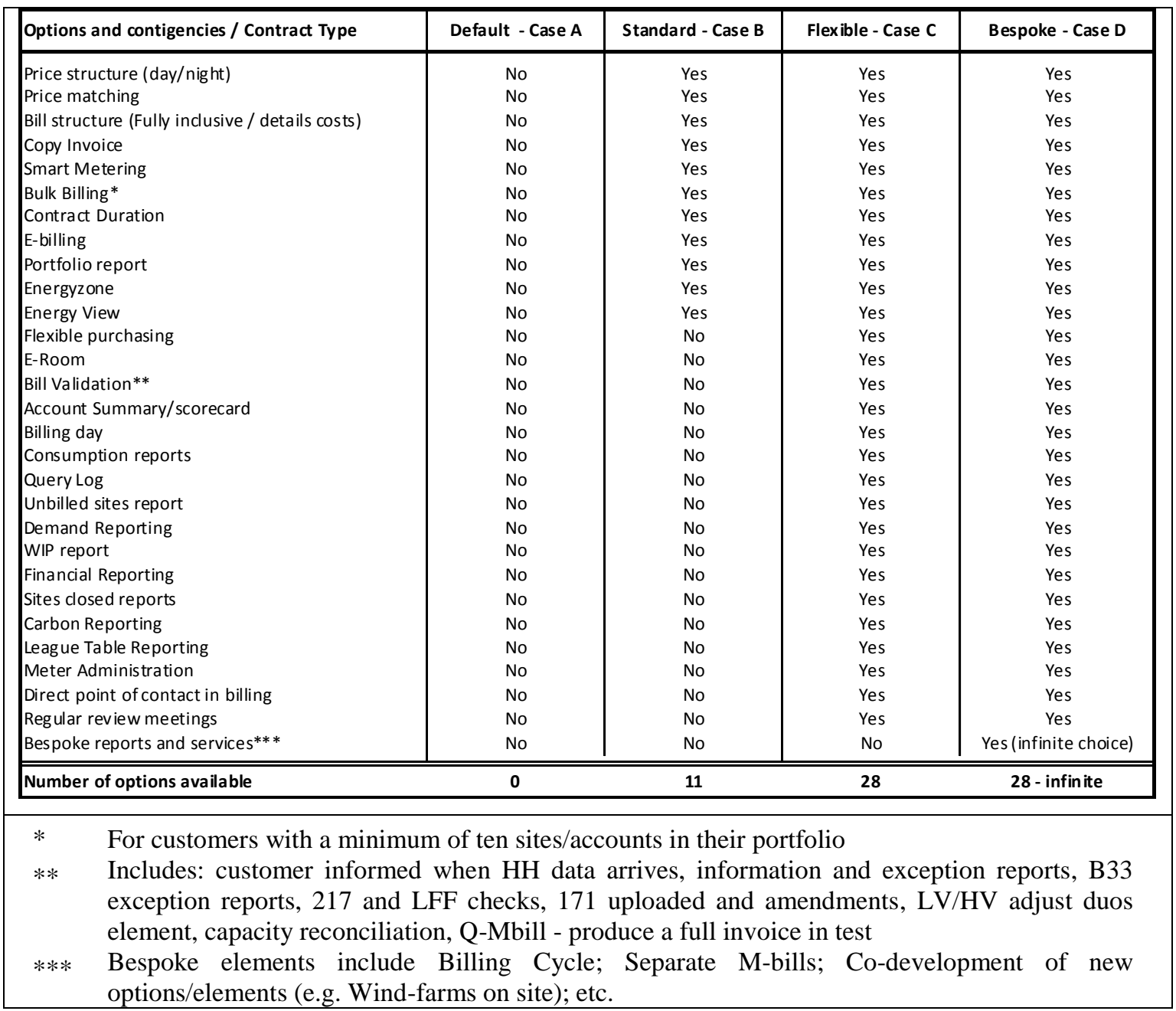

Table 3: List of options available per service concept 


\begin{tabular}{|l|c|c|c|c|}
\hline & Case A & Case B & Case C & Case D \\
\hline $\begin{array}{l}\text { Number of contract managers per } \\
\text { customer served }\end{array}$ & 0 & 0.006 & 0.03 & 0.07 \\
\hline Number of planned encounters & 0 & 1 & $\begin{array}{c}\text { Between } \\
12 \text { and } 16\end{array}$ & $\begin{array}{c}\text { Between } \\
18 \text { and } 24\end{array}$ \\
\hline
\end{tabular}

Table 4: Customer contact strategy

\section{Design characteristics}

The design variables identified in Table 1 are explored and categorised across the four service delivery systems (i.e. the four sets of processes) supporting each individual service concept. To facilitate the understanding and analysis of design variables, simplified conceptual models were developed (see Figures 2 to 5). A model is made up of a number of strata which represent the activities in the process; activities which are customer contact activities (FO) and activities which are non-customer contact activities (BO); the resources that perform these activities and the skill level of employees. Due to constraints of space, we focus here on the design of processes supporting service concepts A and D - those which exhibit the greatest divergence.

\section{Design of sales processes}

Sales processes offer a variety of service packages to different target markets and include the generic activities of customer acquisition, quote production, and contract negotiation. These processes transform customer requirements into a contract. They also set up customer billing accounts on the billing IT system based on contract details. Sales teams perform these processes using two IT systems, a contract management system and a pricing system. The employees in the sales processes are contract managers (CM), sales support (SS), quotation specialists (QS), and customer service advisors (CSA).

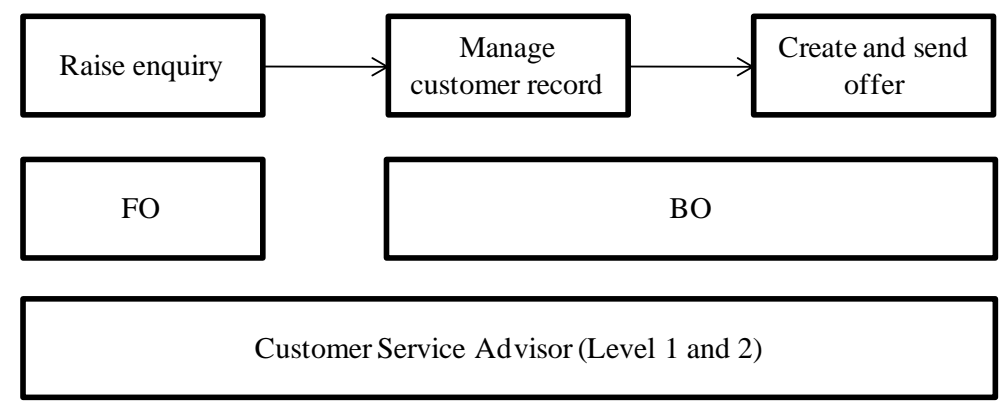

Figure 2: Sales process for service concept A 


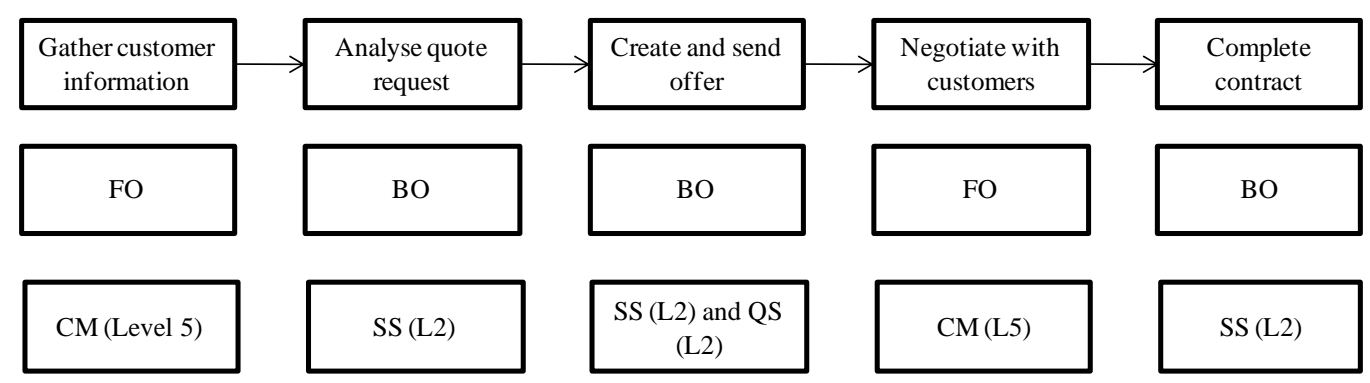

Figure 3: Sales process for service concept D

The data suggests that the process for service concept A is the most routinised. This process is executed following a fixed, non-varying, pre-determined sequence for all customers. The range of tasks performed in the process is limited and highly repeatable from customer to customer. These activities are performed by CSA and assisted through the contract management IT system and the pricing IT system. There is no activity that is entirely performed by an IT system alone. The introduction of an online application form has reduced the need for customer interactions but does not offer the possibility to entirely automate the execution of process steps. Since over 14,000 customers have the same, homogeneous contract, CSA require basic technical skills to perform routine activities. In addition, basic communication skills are needed since the telephone-based service encounters taking place to discuss the offering focus on speedy resolution. These employees occupy entry level positions in the organisation's job family structure. They exercise virtually no discretion over the service offered and over the way they perform their jobs. All employees are required to produce and send the same standard contract to customers. They are required to refer to supervisors if they want to act outside pre-determined timeframes and authorisation limits. Process documentation defines the roles of employees and details how the tasks are to be performed. Compliance is monitored through regular audits. The entire process is performed by CSA who perform both customer contact tasks (e.g. raising enquiry) and non-customer contact tasks (e.g. managing customer records and creating offers). Therefore, the process is highly coupled.

In Case D, the type of activities performed in the sales process changes from customer to customer. Although basic transactional tasks (e.g. collect information, produce a quote) are performed, each customer is dealt with in a personalised way. For instance, customer requirements for energy efficiency and specific purchasing strategies necessitate operational differences to be employed. Similarly the manner in which negotiations are conducted is 
highly customer-specific. Moreover, the process does not follow a fixed, linear sequence as offers may be re-quoted and re-evaluated on a daily basis to reflect market changes. The pricing of these complex offerings is not entirely supported by the pricing system and involves some manual tasks engaging off-line systems. In addition, manual intervention is required when the data held on the contract management system and on the pricing system is inconsistent. A high number of manual checks take place throughout the process to ensure system congruency. Moreover, a high degree of direct interactions with the customer occurs to negotiate service level agreements. In these instances, it is more difficult to automate process tasks because of the complexity of the activities performed and the variety of decisions made by employees. These employees are experts in their field and possess valuable technical and relational skills. Contract managers face challenging problems such as helping customers to be more energy efficient as well as negotiating complex deals to supply a large portfolio of sites with electricity. In addition, a relatively high level of technical skills is required from their sales support teams who perform several complex activities, such as the production of quotes for large offers. The organisation is reliant on the judgement of its staff to successfully execute this process. Contract managers have a high degree of freedom to develop the offering and to manage the relationship with the customer. They are expected to collaborate with the customer in order to create new, innovative products and contract options. For instance, contract managers and customers work together to install wind farms on customer's sites or to develop reporting tools. To achieve this, contract managers are given a great deal of freedom to perform complex tasks, handle the service encounter, and to assess whether the organisation is capable of providing a unique, "never been asked before" service. These employees may develop new ways of working to fulfil customer needs and process compliance is much more loosely controlled. The process is decoupled as FO and BO activities are clearly separated out and allocated to different employees to take advantage of their expertise. Sales support staff do all the non-contact, transactional work, such as producing quotes, defining prices, and setting up contracts and billing accounts. This frees up the capacity of the contract manager who, in contrast, can focus on dealing with existing customers, approaching new customers, and negotiating contract terms with customers.

Case study evidence strongly suggests that there are clear, significant differences in the design characteristics of the sales processes. Table 5 summarises the outcome of data analysis on the design variables studied. 


\begin{tabular}{|c|c|c|c|c|}
\hline & Case A & Case B & Case C & Case D \\
\hline $\begin{array}{l}\text { Degree of } \\
\text { routineness }\end{array}$ & $\begin{array}{l}\text { Fixed, pre- } \\
\text { determined and } \\
\text { repeatable tasks in } \\
\text { the process }\end{array}$ & $\begin{array}{l}\text { Well-defined and } \\
\text { repeatable tasks, } \\
\text { relatively fixed } \\
\text { sequence }\end{array}$ & $\begin{array}{l}\text { Mix of routine and } \\
\text { non-routine tasks in } \\
\text { the process }\end{array}$ & $\begin{array}{l}\text { Tasks vary from } \\
\text { customer to } \\
\text { customer. }\end{array}$ \\
\hline $\begin{array}{l}\text { Degree of } \\
\text { automation }\end{array}$ & $\begin{array}{l}\text { Tasks performed by } \\
\text { employees and } \\
\text { assisted through } \\
\text { systems. Very few } \\
\text { customer } \\
\text { interactions. }\end{array}$ & $\begin{array}{l}\text { Tasks performed by } \\
\text { employees and } \\
\text { assisted through } \\
\text { systems. Limited } \\
\text { customer } \\
\text { interactions. }\end{array}$ & $\begin{array}{l}\text { Tasks performed by } \\
\text { employees and } \\
\text { assisted through } \\
\text { systems. Frequent } \\
\text { customer } \\
\text { interactions and } \\
\text { manual work } \\
\text { required. }\end{array}$ & $\begin{array}{l}\text { Tasks performed by } \\
\text { employees and } \\
\text { assisted through } \\
\text { systems. Ongoing } \\
\text { customer } \\
\text { interactions and } \\
\text { manual work } \\
\text { required. }\end{array}$ \\
\hline Level of skills & $\begin{array}{l}\text { Basic PC and } \\
\text { telephone skills }\end{array}$ & $\begin{array}{l}\text { Advanced analytical } \\
\text { skills. Good } \\
\text { knowledge of } \\
\text { industry. Good } \\
\text { telephone and } \\
\text { negotiating skills }\end{array}$ & $\begin{array}{l}\text { Very good } \\
\text { knowledge of } \\
\text { industry and market. } \\
\text { Excellent } \\
\text { communication and } \\
\text { negotiation skills }\end{array}$ & $\begin{array}{l}\text { Employees are } \\
\text { experts. Extensive } \\
\text { knowledge of } \\
\text { industry and market. } \\
\text { Excellent negotiation } \\
\text { and influencing } \\
\text { skills }\end{array}$ \\
\hline $\begin{array}{l}\text { Level of } \\
\text { discretion }\end{array}$ & $\begin{array}{l}\text { No discretion over } \\
\text { both offering and } \\
\text { process }\end{array}$ & $\begin{array}{l}\text { Limited discretion } \\
\text { over both offering } \\
\text { and process }\end{array}$ & $\begin{array}{l}\text { Relatively high } \\
\text { discretion over both } \\
\text { offering and process }\end{array}$ & $\begin{array}{l}\text { Very high discretion } \\
\text { over both offering } \\
\text { and process }\end{array}$ \\
\hline $\begin{array}{l}F O-B O \\
\text { configurations }\end{array}$ & Highly coupled & Coupled & Decoupled & Decoupled \\
\hline
\end{tabular}

Table 5: Design characteristics of sales processes

\section{Design of billing processes}

Billing processes produce and deliver bills and billing reports to customers based on customer's consumption data which is automatically fed into the IT billing system by thirdparty service providers. Bills are produced either automatically or manually using these data. Employees in the billing processes are customer service advisors (CSA), billing managers (BM), and service development managers (SDM) (see Figures 4 and 5).

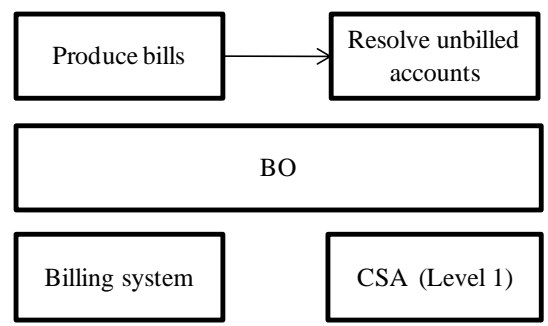

Figure 4: Billing process for service concept A 


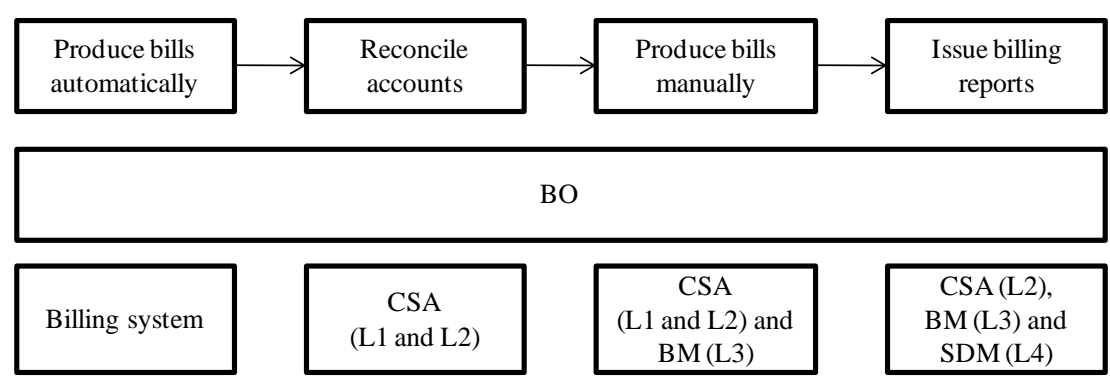

Figure 5: Billing process for service concept D

In Case A the process is fully automated and highly routinised. All bills are produced and delivered through the automated IT system. The process continuously handles highly repetitive, similar billing tasks which are tightly defined and fixed. Manual intervention is limited to the resolution of billing errors identified by the IT system. Every month circa $10 \%$ of accounts fail to bill automatically and require a CSA to manually resolve the error. Overall, 12 CSA are responsible for the maintenance and administration of 11,226 customers (i.e. a ratio of 0.001 employee per customer served). CSA have a basic level of technical skills which are required to analyse and resolve these errors. These employees cannot modify the service package delivered to the customer. In addition, their discretion over the process is limited because most decisions have been automated. The billing system stops accounts automatically billing if certain elements of the bill fall outside pre-determined parameters. As illustrated in Figure 4, the billing process can be described as a back-office process. All of the activities are non-customer contact activities.

In Case D, many tasks are well-defined and relatively fixed because the principle of billing is basically the same. Nonetheless, the process handles a great variety of tasks which vary from customer to customer, depending on individualised service level agreements. For instance, billing reports, bill due dates, and billing cycles are customer-specific. Similarly, the process steps for manually producing bills and reports usually differ from customer to customer. Requirements also change during the life of the contract which forces the process to be adapted. Regarding process automation, $57 \%$ of customers have their bills entirely manually processed and produced. Moreover, while $43 \%$ of bills are produced automatically through the system, these incur manual work which includes reconciling accounts, checking prices, generating multi-bills, and creating billing reports. Overall, 7 employees are responsible for the billing of 7 customers (i.e. a ratio of 1 employee per customer). Most billing activities require a relatively low level of technical skills from CSA, who carry out relatively 
straightforward tasks such as verifying prices or reconciling accounts. Billing managers who are highly experienced billing specialists are also heavily involved in the day-to-to running of the process, as they perform more challenging tasks such as completing billing reports, verifying complex bills, and resolving intricate billing errors.. In addition, service development managers (SDM) are responsible for the maintenance and management of individual customer accounts. These employees possess advanced analytical skills as they have to determine how the process can best deliver on customer-specific service level agreements. Both the billing manager and the SDM have the authority to implement changes in process execution to achieve the performance levels specified in the service level agreements. As illustrated in Figure 5, the billing process can be described as a back-office process. All of the activities are non-customer contact activities.

Case study data suggests that there are clear, significant differences in the design characteristics of the billing processes. Table 6 summarises the outcome of data analysis on the design variables studied.

\begin{tabular}{|l|l|l|l|l|}
\hline & \multicolumn{1}{|c|}{ Case A } & \multicolumn{1}{|c|}{ Case B } & \multicolumn{1}{c|}{ Case C } & \multicolumn{1}{c|}{ Case D } \\
\hline $\begin{array}{l}\text { Degree of } \\
\text { routineness }\end{array}$ & $\begin{array}{l}\text { Fixed, pre- } \\
\text { determined and } \\
\text { repeatable process }\end{array}$ & $\begin{array}{l}\text { Fixed, pre- } \\
\text { determined and } \\
\text { repeatable process. } \\
\text { Aggregate bills } \\
\text { created for a limited } \\
\text { number of customers } \\
\text { only. }\end{array}$ & $\begin{array}{l}\text { Groups of customers } \\
\text { are billed the same } \\
\text { way. Significant } \\
\text { differences across } \\
\text { groups in task type } \\
\text { and process } \\
\text { execution. }\end{array}$ & $\begin{array}{l}\text { Many routine tasks } \\
\text { but tasks and process } \\
\text { execution varies } \\
\text { from customer to } \\
\text { customer }\end{array}$ \\
\hline $\begin{array}{l}\text { Degree of } \\
\text { automation }\end{array}$ & $\begin{array}{l}\text { Fully automated } \\
\text { process }\end{array}$ & $\begin{array}{l}\text { Highly automated } \\
\text { process, some } \\
\text { manual work }\end{array}$ & $\begin{array}{l}\text { Process mostly } \\
\text { automated, manual } \\
\text { work on every bill }\end{array}$ & $\begin{array}{l}\text { Mix of automated } \\
\text { and manual process }\end{array}$ \\
\hline $\begin{array}{l}\text { Level of skills } \\
\text { Bevel of } \\
\text { discretion }\end{array}$ & $\begin{array}{l}\text { Basic technical skills } \\
\text { both offering and } \\
\text { process }\end{array}$ & $\begin{array}{l}\text { Mostly basic } \\
\text { technical skills }\end{array}$ & $\begin{array}{l}\text { Mix of basic and } \\
\text { advanced skills }\end{array}$ & $\begin{array}{l}\text { Mix of basic and } \\
\text { advanced skills }\end{array}$ \\
\hline and process & $\begin{array}{l}\text { Liscretion } \\
\text { over package } \\
\text { delivered, some } \\
\text { discretion over } \\
\text { process }\end{array}$ & $\begin{array}{l}\text { Limited discretion } \\
\text { over package } \\
\text { delivered, high } \\
\text { discretion over } \\
\text { process }\end{array}$ \\
\hline $\begin{array}{l}\text { FO-BO } \\
\text { configurations }\end{array}$ & Back-office process & Back-office process & Back-office process & Back-office process \\
\hline
\end{tabular}

Table 6: Design characteristics of billing processes 


\section{Discussion}

Our approach is consistent with an integrated view of service design (Cook et al., 1999), since the design characteristics are studied in relation to the service concepts offered to specific target markets, and not in isolation. The empirical findings suggest that extent of customisation of the service concept is a primary influence on the design characteristics of the service delivery system. Each individual service offering is supported by service delivery systems exhibiting markedly different design characteristics. Since different service concepts lead to different designs, the empirical evidence supports the theoretical relationships postulated by the service strategy triad and resonates with much of the existing literature (Armistead, 1990; Heskett, 1987, Goldstein et al., 2002, Roth and Menor, 2003). The more customised the service concept, the greater the employee skills, the greater the employee discretion, the less routinized tasks, and the less opportunity for automation. Essentially, the greater the customisation the more the service delivery systems are discretionary, subjective, and uniquely designed. Similarity is observed between this research and the work of Hall and Johnson (2009). The case organisation employs a rigid sales process for low-risk, low-reward sales efforts (i.e. Case A) and a flexible process for high-risk, high-reward sales efforts (i.e. Case D). These processes require different designs because they support the realisation of different service concepts. We, therefore, concur with Hall and Johnson (2009) who assert that integrating or merging such processes would be counterproductive. Attempting to compete on multiple service concepts with an organisation-wide, homogeneous design would constrain performance.

While confirmatory evidence is found for the alignment of the service concept - service delivery system design components, the findings provide additional insights into the contingencies and characteristics of service delivery system design. We now consider how the dimensions of the service concept (i.e. complexity of the offering and customer relationship strategy) influence the level of technical and interpersonal skills, the extent of employee discretion, the potential for automation, and the degree of routineness in the service delivery system. The findings suggest that customers with heterogeneous and sophisticated customer requirements require a complex offering typified by multiple configurable parameters as well as a high-level, very involved relationship with multiple exchanges taking place over contract life. First, as a result of the complexity of the service contract, advanced and highly-specialised technical skills are required from employees. Employees need to have a thorough understanding of the offering, market, and industry to ensure that they are able to 
comprehend detailed customer requirements, translate these requirements into service level agreements, negotiate terms and conditions, and carry out challenging pricing and billing tasks. The link between complex contracts and high level of technical knowledge resonates with several conceptual frameworks (Buzacott, 2000; Kellogg and Nie, 1995; Silvestro, 1999). Second, excellent interpersonal and negotiation skills are required to develop and maintain a high-level ongoing relationship with the customer. Confirming the research of Metters and Vargas (2000), we have found evidence that allocating all of the customercontact tasks to specific front-office employees who are responsible for individual customer accounts helps to develop a personal understanding of customer needs and expectations. Because employees must solicit customer ideas and interact with the customer dynamically, defining the specifications of the service concept necessitates excellent interpersonal skills (Chase and Tansik, 1983; Kellogg and Nie, 1995). Third, in such instances, it is essential that employees exercise professional judgement and benefit from significant discretion as they perform unstructured tasks and deal with unpredictable customer demands. Employees need the freedom to determine how the service delivery system should operate to achieve the performance levels specified in bespoke service level agreements. This is consistent with the view that the service employee needs decision-making authority to evaluate whether and how a unique service can actually be created and delivered (Buzacott, 2000; Silvestro, 1999; Wemmerloev, 1990). Since employees are directly involved in the creation of the offering and in the formulation of the service level agreements, they require significant freedom to handle the service encounter, as suggested by Silvestro (1999). This resonates with Bowen and Lawler (1995) who posit that empowering employees is effective in situations where developing close customer relationships is essential. Fourth, several factors reduce the potential for automating service delivery tasks. A number of complex decisions are required in the service delivery system. Work flow systems (e.g. contract management and billing IT systems) can support the activities but they do not automate decision tasks. In addition, it is difficult to find sufficiently-flexible pricing and billing IT systems that can cope with the multiplicity of configurable parameters which impact both the pricing structure of the offering and the billing of customer accounts. Recurrent manual intervention, such as verifying that agreed service levels are met, is necessary to mitigate the risk of errors. Finally, as postulated by Apte and Vepsäläinen (1993), the "human advisory" component is important in configuring individualised service level agreements. In this context, the role of employees, as opposed to technology, is essential in managing a person-to-person relationship with the customer. These findings provide support for the view that it is often difficult to find 
automated systems capable of handling the high variability in customer requirements associated with customised, complex service offerings (Buzacott, 2000; Huete and Roth, 1988; Sampson and Froehle, 2006). Fifth, high variety in demands across the customer base (in terms of pricing structures and reconciliations for instance) frequently changes the type of activities performed. Moreover, each customer is treated in a personalised manner. Most interactions are customer-driven and directly influence the nature and sequencing of the tasks. As suggested by Buzacott (2000), this customer-induced variability creates significantly more diversity in the tasks to execute and requires the process to have increased exception-handling capability.

In contrast, these findings show that customers with homogenous requirements have a limited influence on the specifications of the service concept. These customers require generic service contracts with a restricted number of configurable options as well as a transactionbased relationship with the service provider. First, as a result of the simplicity and homogeneity of the specifications of the service offering, no particular expertise or knowledge are desired from employees to set-up contracts, produce bills, and resolve billing issues. These employees occupy "entry level positions" and complete simple, standard operations (Napoleon and Gaimon, 2004). They are similar to Wemmerloev's (1990, p.34) definition of "service workers" who "spend all their working hours in front of a computer screen". Second, since the customer relationship is primarily transactional and the customeremployee interface is less personalised, basic telephone communication skills are needed to conduct the sale. This resonates with Kellogg and Nie (1995) who postulate that in situations where opportunities for interactions are limited service employees possess relatively basic interpersonal skills. Third, service specifications are largely pre-determined by the service provider which leaves little room for employee discretion in the sales process. In the billing process, the need for employees with decision-making authority is eliminated through the use of a highly-mechanised process which automates decisions. This resonates with Napoleon and Gaimon (2004) who note that decisions relating to the configuration and production of standard service bundles are routine and are likely to be automated. Fourth, limited variability in customer requests as well as in contracts offered and in bills produced, makes it possible to precisely specify and to tightly define tasks and activities. Fifth, it follows that processes supporting standardised offerings have a higher potential for automation because of the repetitive nature of the tasks which are executed in a fixed, non-varying sequence. This is consistent with a production-line approach which states that in these contexts technology 
should substitute for people (Bowen and Youngdahl, 1998). The empirical evidence supports the view that processes delivering standard service offerings are more suitable for automation (Buzacott, 2000; Kellogg and Nie, 1995).

Based on the case study evidence, a framework emphasising the contingencies and characteristics of service delivery system design is proposed below (see Figure 6).

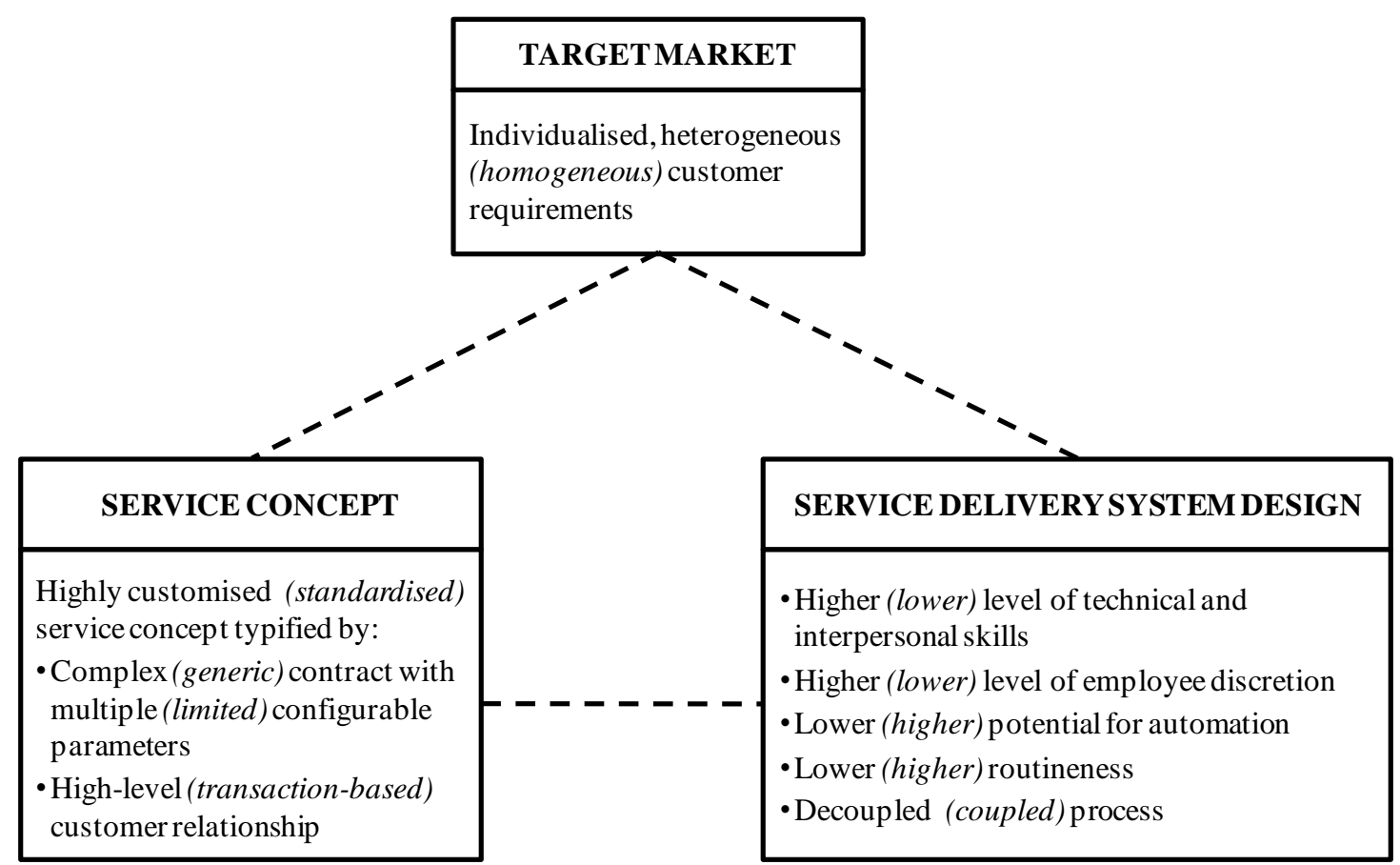

Figure 6: Service delivery system design: contingencies and characteristics

This empirically-grounded framework leads to the following research proposition.

Proposition 1: The more customised the service concept; the higher the level of skills, the greater the employee discretion, the less task routineness, and the less opportunity for automation, in the service delivery system. And conversely, the more standardised the service concept; the lower the level of skills, the more limited the employee discretion, the more task routineness, and the more opportunity for automation in the service delivery system.

Furthermore, these findings offer two major points of departure from current back-office and front-office design theory. First, this study provides new insights into the design of the backoffice, which contradict existing SOM theory. There is consensus in SOM that back office, low customer contact processes can be made as efficient as assembly lines in manufacturing 
using mass production design principles such as automation and routinisation (Bowen and Youngdhal, 1998; McLaughlin, 1996) since "the presence of the customer is the dominant constraint on the efficiency of the process" (Chase, 1981). Accordingly, the back-office is often referred to as a "service factory" (Kellogg and Nie, 1995; Schmenner, 1986; Silvestro, 1999). Verma and Young (2000) argue that this perspective assumes that low-contact service systems form a homogeneous group, have similar design requirements, and are always designed for efficiency. Our findings, however, provide empirical evidence that low-contact service systems delivering customised service concepts are less amenable to automation, less likely to be designed for efficiency, and do not exhibit the characteristics of a "service factory". While the four billing processes studied in this research can be described as backoffice processes, the importance of efficiency is not consistent in all four processes. Billing processes supporting standardised offerings resemble "service factories" as they focus on efficiency and cost reduction (Karmarkar and Pitbladdo, 1995). These processes offer a high potential for automation and achieve higher efficiency. Specifically, the cost to serve the customer is significantly lower in the case of the standardised service concept because fewer employees are required to execute the process, as evidenced by the 'employee per customer' ratios. This is because the organisation is able to take advantage of the uniformity and rigidity of the billing activities to fully automate these processes. In contrast, processes supporting customised offerings do not manifest such characteristics. Significantly more fluid processes are necessary to deliver on complex and individualised Service Level Agreements (SLA). Although these processes are isolated from customer presence, the variety and complexity of tasks performed significantly reduces the opportunity for automation. In other words, it is necessary to allow sufficient flexibility in the process to perform against the outcomes detailed in the SLA. Complex offerings typified by numerous, configurable parameters cannot be put through an IT system with inherent rigidity. A great deal of manual work is carried out by highly-skilled billing experts to achieve the performance levels specified in the SLA and to mitigate the risk of errors. This manual work is a major cost driver. For instance, producing and verifying complex aggregate bills, generating individualised performance reports, reconciling customer accounts, and maintaining the currency of billing accounts necessitate a significant amount of manual intervention by billing specialists. Against this background, achieving the same efficiency levels as an automated process is simply not possible. Rather, the focus is on meeting sophisticated, sometimes unique, customer requirements. As a billing manager succinctly expressed it: "we cannot deliver on the service level agreements with rigid processes". 
Proposition 2: Low customer-contact service systems delivering customised service concepts have less opportunity for automation, require a higher skill level, and are less concerned with efficiency gains than low-contact service systems delivering standardised service concepts.

Second, this study extends existing theory related to the configuration of front office and back office work in the service delivery system. Our findings contradict traditional SOM theory which argues that contact and non-contact jobs call for different sets of activities which are to be allocated to different employees (Chase and Tansik, 1983). This is so that front office personnel can focus on the customer and back office work can be rationalised and managed for cost reduction and efficiency gains (McLaughlin, 1996). The findings presented here are consistent with the work of Zomerdijk and de Vries (2007) and of Metters and Vargas (2000) who demonstrate that diverse FO-BO designs are appropriate under different strategic conditions. In our data coupling and decoupling approaches were identified in the sales processes to maximise process efficiency and to improve customer service respectively. In the sales process supporting the standardised service concept customer contact and noncustomer contact tasks are kept coupled to maximise the productivity of staff through task switching enabling idle time reduction. This leads to a better utilisation of capacity and a tighter control of costs (as suggested by Zomerdijk and Vries, 2007). These configurations are similar to the "kiosk" type described by Metters and Vargas (2000). In contrast, the sales process supporting the customised service concept is decoupled since FO and BO activities are allocated to different employees to take advantage of their expertise. This process exhibits characteristics of the "focused professional" type (Metters and Vargas, 2000) as non-contact work is decoupled "with a primary goal to support the front office, rather than cost control" (p.675). In addition, support is found for the idea that the design of the interface between front office employees (i.e. contract manager) and back office employees (i.e. sales support) is important in these situations. Individual, dedicated back office workers are assigned to each front office employee. In other words, small sales teams consisting of the pair "contract manager - sales support employee" are constituted to deal with individual customers. Different combinations of specialisation depending upon the service concept are observed (which is also consistent with the findings of Zomerdijk and de Vries, 2007) showing that decoupled processes for customised service concepts may establish sales teams to facilitate coordination and the handover of work. Such close links contribute to enhancing flexibility and customer service (Metters and Vargas, 2000). 
Moreover, our research also extends further the work of Metters and Vargas (2000). By linking the FO-BO design decision to the strategy of the firm these authors state that there are inherent difficulties in adopting different FO-BO configurations within the same organisation. Contrary to this assertion, we found coupled and decoupled front and backoffices in the sales processes of the case organisation. This strongly suggests that it is viable for a large organisation to adopt different FO-BO designs (i.e. the "kiosk" and "focused professional" types in this case study) simultaneously. While Metters and Vargas associate the decoupling decision with "individual firm strategy" (p.664), our empirical evidence suggests that FO-BO configurations are determined according to the service concept. The service concept is often seen as a link between strategy and service system design (Roth and Menor, 2003) and a single organisation may provide distinct service concepts to different customers. Designing FO and BO activities, therefore, requires an understanding of the strategy of the service organisation as embodied in the specification of the service concepts. Different FO-BO configurations within the same organisation are appropriate for supporting different service concepts.

Proposition 3: Multiple front office - back office configurations are possible in the same organisation.

The three research propositions derived from our empirically-grounded framework reflect the influence of the service concept on the design characteristics of the service delivery system. In addition, they reflect the challenges to existing FO-BO design theory identified from the empirical evidence. These propositions require additional, theory-testing research to establish the generasibility of the results.

\section{Implications for managers}

The results have implications for managers involved in the design of service delivery systems. While the research does not prescribe a set of design characteristics for service delivery systems, it seeks to influence practice and to foster the thinking of managers by helping them conceptualise service system design issues. First, the study emphasises the need to consider the specifications of the service concept and the unique characteristics of their delivery processes to design an effective service delivery system. The most important issues concern the complexity of the offering and the customer relationship strategy which have considerable implications for all the aspects of service system design. Second, we consider the importance of taking a process view to explore design challenges inherent to service 
delivery systems. Processes are what an organisation does (Armistead and Machin, 1997). While the issue of process is often central in service organisations (Maddern et al., 2007), few empirically-derived principles of process design are available to managers involved in the delivery of services. A process perspective is beneficial from a design standpoint because it helps to understand the heterogeneity inherent in service delivery systems providing multiple service concepts. Based on the findings of this study, it is clear that identifying design characteristics at the level of the whole organisation is a significant challenge. It would be difficult to characterise the entire service system clearly because it comprises multiple, heterogeneous processes.

\section{Limitations}

This study has five major limitations. First, we assumed that alignment between service concept and service system design was realised because the chosen company is the market leader in its sector. We are confident that this assumption is reasonable within the $\mathrm{OM}$ contingency paradigm that links "good" practice to performance (Sousa and Voss, 2008). Nonetheless, we acknowledge that it is a limitation. Second, we recognise that the processes of the organisation studied are interrelated and that there are clearly major interactions between the four service delivery systems supporting each individual service concept. As a result, the organisation is likely to incorporate a number of trade-offs in making design decisions. This perspective has not been considered in this research which focuses on the specific design characteristics of the delivery systems supporting each individual service concept. This research does not examine the trade-offs between the various designs of the service delivery system. Similarly, it does not explore how a single service delivery system delivers against multiple service concepts. Recognising this deficiency, we nonetheless believe that we first need to consider the design problems in isolation (i.e. the specific design of each service system) before we consider the problems in interaction (i.e. the design of the whole service delivery system). Third, our study takes a market-led, outside-in view of strategy based on market positioning and customer requirements (see for example, Tranfield and Smith, 1998). This position assumes that the service concept directly influences service system design. However, organisations that are not in a 'green field' will be adding additional service concepts to an existing portfolio. They will have existing capabilities which might influence the services that they can offer. Design decisions can be seen as a necessary interplay between the inside-out and outside-in perspectives. Whilst the inside-out perspective has not been considered, it is important to recognise that the relationship between 
service concept and service delivery system design is not always unidirectional. Fourth, we acknowledge that the process construct is a very challenging unit of empirical analysis. In this research we are simply distinguishing between two high-level processes, selling and billing. In addition, there are important difference between processes in principle and processes in practice which have serious implications for the empirical data. This research is concerned with processes in principle and was designed to understand how processes were designed, not how they run in practice. The gap between processes as they were designed and as they are occurring in practice (that is the compliance to the design) was not the subject of this research. Fifth, this study explores the characteristics and contingencies of service system design in a B2B environment. B2B businesses provide products and services to other businesses whereas $\mathrm{B} 2 \mathrm{C}$ businesses provide products and services to end user consumers (Parasuraman and Zinkhan, 2002). We recognise that service concepts in B2B context may be significantly different than in B2C context (Eckles, 1990; Minett, 2002). However this research is not concerned with these differences and their implications for service system design. The focus is on how distinct service concepts require different designs of the service system, regardless of whether the service concepts are B2B or B2C. Four B2B service concepts were chosen to provide a constant business environment and allow for like-for-like comparisons.

\section{Conclusion}

This research empirically grounds the service strategy triad conceptual model and extends current understanding of service delivery system design characteristics and contingencies. This provides a significant extension to the current model and establishes a platform for both future theoretical analysis and practical implementation. First, the results indicate what design characteristics are contingent on the service concept and show how each individual design characteristic is influenced by the service concept. In the case of customised service concepts, the design characteristics of the corresponding service delivery system are advanced technical and interpersonal employee skills, a high degree of employee discretion, a low level of task routineness, and limited opportunities for automation. In contrast, service delivery systems supporting standardised service concepts exhibit a basic level of technical and interpersonal skills, limited employee discretion, high task routineness, and a high potential for automation. Second, our findings directly challenge existing front office - back office theory. The traditional view of the back-office in the existing SOM literature assumes 
that it is always designed for the purpose of efficiency. This research challenges this assumption and shows evidence of back-office processes which are not designed for efficiency. This strongly suggests that the design of the back office is contingent on the service concept. In addition, Metters and Vargas (2000) argue that it is not viable for an organisation to have multiple FO-BO configurations since business strategy is the major driver for the design of FO and BO work. Contrary to this assertion, we provide empirical evidence of different FO-BO configurations supporting distinct service concepts in the case organisation.

While the research contributes to building theory in service design it is clear that no single approach to theory development can produce a well-rounded theory. Further research is needed to test the research propositions derived from this research across a larger sample of service organisations to provide for replication. The study of service delivery system design issues promises to be an exciting avenue for future research trajectories in service operations management. 


\section{References}

Apte, U. and Vepsäläinen, A. P. J. (1993), "High tech or high touch? Efficient channel strategies for delivering financial services", Journal of Strategic Information Systems, Vol. 2 No. 1, pp. 39-54.

Armistead, C. (1990), "Service Operations Strategy: Framework for Matching the Service Operations Task and the Service Delivery System", International Journal of Service Industry Management, Vol. 1 No. 2, pp. 6-16.

Armistead, C. and Machin, S. (1997), "Implications of business process management for operations management", International Journal of Operations and Production Management, Vol. 17 No. 9/10, pp. 886-898.

Bowen, D. E. and Lawler, E. E. (1995), "Empowering service employees", Sloan management review, Vol. 36 No. 4, pp. 73-84.

Bowen, D. E. and Youngdahl, W. E. (1998), “"Lean" service: in defense of a production-line approach", International Journal of Service Industry Management, Vol. 9 No. 3, pp. 207-225.

Brohman, M. K., Piccoli, G., Martin, P., Zulkernine, F. H., Parasuraman, A. and Watson, R. T. (2009), “A Design Theory Approach to Building Strategic Network-based Customer Service Systems", Decision Sciences, Vol. 40 No. 3, pp. 403-430.

Buzacott, J. A. (2000), “Service system structure", International Journal of Production Economics, Vol. 68 No. 1 , pp. 15-27.

Chase, R. B. (1978), "Where does the customer fit in a service operation?" Harvard Business Review, Vol. 56 No. 6, pp. 137-142.

Chase, R. B. (1996), "The mall is my factory: reflections of a service junkie", Production \& Operations Management, Vol. 5 No. 4, pp. 298-308.

Chase, R. B. and Tansik, D. A. (1983), "The customer contact model for organization design", Management Science, Vol. 29 No. 9, pp. 1037-1050.

Chopra, S., Lovejoy, W. and Yano, C. (2004), "Five Decades of Operations Management and the Prospects Ahead", Management Science, Vol. 50 No. 1, pp. 8-14.

Cohen, M. A., Cull, C., Lee, H. L. and Willen, D. (2000), “Saturn's Supply-Chain Innovation: High Value in After-Sales Service ", MIT Sloan Management Review, Vol. 41 No. 4, pp. 93-101.

Collier, D. A. (1994), The Service Quality solution: Using Service Management to gain Competitive Advantage, Irwin, New York: NY.

Collier, D. A. and Meyer, S. M. (1998), “A service positioning matrix", International Journal of Operations and Production Management, Vol. 18 No. 12, pp. 1223-1244.

Collier, D. A. and Meyer, S. M. (2000), “An empirical comparison of service matrices", International Journal of Operations and Production Management, Vol. 20 No. 6, pp. 705-729.

Congram, C. and Epelman, M. (1995), "How to describe your service", International Journal of Service Industry Management, Vol. 6 No. 2, pp. 6-23.

Cook, D. P., Goh, C.-H. and Chung, C. H. (1999), "Service Typologies: A State of the Art Survey", Production \& Operations Management, Vol. 8 No. 3, pp. 318-338.

Eckles, R.W. (1990), Business marketing management: Marketing of business products and services, Prentice Hall, Englewood Cliffs: N.J.

Edvardsson, B. and Olsson, J. (1996), "Key Concepts for New Service Development", Service Industries Journal, Vol. 16 No. 2, pp. 140-164.

Eisenhardt, K. M. (1989), "Building Theories from Case Study Research", Academy of Management Review, Vol. 14 No. 4, pp. 532-50.

Flick, U. (2006), An Introduction to Qualitative Research, Sage, London.

Frei, F. X. and Harker, P. T. (1999), "Measuring the Efficiency of Service Delivery Processes: An Application to Retail Banking", Journal of Service Research, Vol. 1 No. 4, pp. 300-312. 
Goldstein, S. M., Johnston, R., Duffy, J. and Rao, J. (2002), “The service concept: the missing link in service design research?" Journal of Operations Management, Vol. 20 No. 2, pp. 121-134.

Gummesson, E. (1990), “Service Design", The Total Quality Magazine, Vol. 2 No. 2, pp. 97-101.

Hall, M. J. and Johnson, M. E. (2009), "When Should a Process Be Art, Not Science?" Harvard Business Review, Vol. 87 No. 3, pp. 58-65.

Hill, A. V., Collier, D. A., Froehle, C. M., Goodale, J. C., Metters, R. D. and Verma, R. (2002), "Research opportunities in service process design", Journal of Operations Management, Vol. 20 No. 2, pp. 189202.

Huete, L. M. and Roth, A. V. (1988), "The Industrialisation and Span of Retail Banks' Delivery Systems", International Journal of Operations and Production Management, Vol. 8 No. 3, pp. 46-66.

Johansson, P. and Olhager, J. (2004), "Industrial service profiling: Matching service offerings and processes", International Journal of Production Economics, Vol. 89 No. 3, pp. 309-320.

Johnston, R. (1994), "Operations: From Factory to Service Management", International Journal of Service Industry Management, Vol. 5 No. 1, pp. 49-63.

Johnston, R. and Clark, G. (2005), Service Operations Management: Improving Service Delivery, FT Prentice Hall, Harlow, England.

Karmarkar, U. S. and Pitbladdo, R. (1995), "Service markets and competition", Journal of Operations Management, Vol. 12 No. 3-4, pp. 397-411.

Karwan, K. R. and Markland, R. E. (2006), "Integrating service design principles and information technology to improve delivery and productivity in public sector operations: The case of the South Carolina DMV", Journal of Operations Management, Vol. 24 No. 4, pp. 347-62.

Kellogg, D. L. and Nie, W. (1995), "A framework for strategic service management", Journal of Operations Management, Vol. 13 No. 4, pp. 323-337.

Kwortnik, R. J. and Thompson, G. M. (2009), "Unifying service marketing and service operations with service experience management", Journal of Service Research, Vol. 4 No. 11, pp. 389-406.

Lovelock, C. H. (1983), “Classifying Services to Gain Strategic Marketing Insights", Journal of Marketing, Vol. 47 No. 3, pp. 9-20.

Machuca, J. A. D., Gonzalez-Zamora, M. M. and Aguilar-Escobar, V. G. (2007), "Service Operations Management research", Journal of Operations Management, Vol. 25 No. 3, pp. 585-603.

Maddern, H., Maull, R., Smart, A. and Baker, P. (2007), "Customer satisfaction and service quality in UK financial services", International Journal of Operations and Production Management, Vol.27 No. 9, pp. 999-1019.

McLaughlin, C. P. (1996), "Why variation reduction is not everything: a new paradigm for service operations", International Journal of Service Industry Management, Vol. 7 No. 3, pp. 17 - 30.

Meredith, J. (1998), "Building operations management theory through case and field research", Journal of Operations Management, Vol. 16 No. 4, pp. 441-454.

Metters, R. and Vargas, V. (2000), "A typology of de-coupling strategies in mixed services", Journal of Operations Management, Vol. 18 No. 6, pp. 663-682.

Miles, M. B. and Huberman, A. M. (1994), Qualitative Data Analysis - An Expanded Sourcebook, Sage, Newbury Park: CA.

Minett, S. (2002), B2B: a radically different approach for business-to-business marketers, Financial Times/Prentice Hall.

Napoleon, K. and Gaimon, C. (2004), "The Creation of Output and Quality in Services: A Framework to Analyze Information Technology-Worker Systems", Production \& Operations Management, Vol. 13 No. 3, pp. 245-259.

Nie, W. and Kellogg, D. L. (1999), "How professors of operations management view service operations?" Production \& Operations Management, Vol. 8 No. 3, pp. 339-355. 
Parasuraman, A. and Zinkhan, G.M. (2002), "Marketing to and serving customers through the internet: An overview and research agenda", Journal of the Academy of Marketing Science, Vol. 30 No. 4, pp. 286295.

Ramaswamy, R. (1996), Design and management of service processes: keeping customers for life, AddisonWesley, Reading, MA.

Roth, A. V. and Menor, L. J. (2003), "Insights into service operations management: a research agenda", Production \& Operations Management, Vol. 12 No. 2, pp. 145-164.

Safizadeh, M. H., Field, J. M. and Ritzman, L. P. (2003), “An empirical analysis of financial services processes with a front-office or back-office orientation", Journal of Operations Management, Vol. 21 No. 5, pp. 557-576.

Sampson, S. E. and Froehle, C. M. (2006), "Foundations and Implications of a Proposed Unified Services Theory", Production \& Operations Management, Vol. 15 No. 2, pp. 329-343.

Sasser, E. W., Olsen, P. R. and Wyckoff, D. D. (1978), Management of Service Operations: Text, Cases, and Readings, Allyn \& Bacon, Boston, MA.

Schmenner, R. W. (1986), "How Can Service Businesses Survive and Prosper?" Sloan Management Review, Vol. 27 No. 3, pp. 21-32.

Shostack, G. L. (1987), "Service Positioning Through Structural Change", Journal of Marketing, Vol. 51 No. 1, pp. 34-43.

Silvestro, R. (1999), "Positioning services along the volume-variety diagonal", International Journal of Operations and Production Management, Vol. 19 No. 3/4, pp. 399-420.

Silvestro, R., Fitzgerald, L., Johnston, R. and Voss, C. A. (1992), “Towards a classification of service processes", International Journal of Service Industry Management, Vol. 3 No. 3, pp. 62-75.

Silvestro, R. and Silvestro, C. (2003), "New service design in the NHS: an evaluation of the strategic alignment of NHS Direct", International Journal of Operations and Production Management, Vol. 23 No. 4, pp. 401-17.

Sousa, R. and Voss, C. A. (2008), "Contingency research in operations management practices", Journal of Operations Management, Vol. 26 No. 6, pp. 697-713.

Tax, S. S. and Stuart, I. (1997), "Designing and Implementing New Services: The Challenges of Integrating Service Systems", Journal of Retailing, Vol. 73 No. 1, pp. 105-134.

Tinnilae, M. and Vepsäläinen, A. P. J. (1995), “A model for strategic repositioning of service processes", International Journal of Service Industry Management, Vol. 6 No. 4, pp. 57-80.

Tranfield, D. and Smith, S. (1998), "The strategic regeneration of manufacturing by changing routines", International Journal of Operations and Production Management, Vol. 18 No. 2, pp. 114-129.

Verma, R., Fitzsimmons, J., Heineke, J. and Davis, M. (2002), "New issues and opportunities in service design research", Journal of Operations Management, Vol. 20 No. 2, pp. 117-120.

Verma, R. and Thompson, G. M. (1999), "Managing service operations based on customer preferences", International Journal of Operations \& Production Management, Vol.19 No. 9, pp. 891-908.

Verma, R. and Young, S. T. (2000), "Configurations of low-contact services", Journal of Operations Management, Vol.18 No. 6, pp. 643-61.

Voss, C., Tsikriktsis, N. and Frohlich, M. (2002), "Case research in operations management", International Journal of Operations \& Production Management, Vol. 22 No. 2, pp. 195-219.

Wemmerloev, U. (1990), “A Taxonomy for Service Processes and its Implications for System Design", International Journal of Service Industry Management, Vol. 1 No. 3, pp. 20-40.

Yin, R. K. (2003), Case study research: design and methods, Sage Publications, Thousand Oaks: CA.

Zomerdijk, L. G. and de Vries, J. (2007), "Structuring front office and back office work in service delivery systems", International Journal of Operations and Production Management, Vol. 27 No. 1, pp. 108-131. 